\title{
Development of epoxyeicosatrienoic acid analogs with in vivo anti-hypertensive actions
}

\section{John D. Imig ${ }^{1}$, Ahmed Elmarakby ${ }^{2}$, Kasem Nithipatikom ${ }^{1}$, Shouzou Wei ${ }^{3}$, Jorge H. Capdevila ${ }^{3}$, Venugopal Raju Tuniki ${ }^{4}$, Bhavani Sangras ${ }^{4}$, Siddam Anjaiah ${ }^{4}$, Vijaya L. Manthati ${ }^{4}$, D. Sudarshan Reddy ${ }^{4}$ and John R. Falck ${ }^{4}$}

'Department of Pharmacology and Toxicology, Medical College of Wisconsin, Milwaukee, WI, USA

${ }^{2}$ Department of Oral Biology, Medical College of Georgia, Augusta, GA, USA

${ }^{3}$ Department of Medicine, Division of Nephrology and Hypertension, Vanderbilt University, Nashville, TN, USA

${ }^{4}$ Department of Biochemistry, University of Texas Southwestern Medical Center, Dallas, TX, USA

\section{Edited by:}

Yi Zhu, Peking University, Health

Science Center, China

\section{Reviewed by:}

Yu Huang, Chinese University of Hong-Kong, China

John M. Seubert, University of Alberta,

Canada

Xueying Zhao, Morehouse School of

Medicine, USA

\section{*Correspondence:}

John D. Imig, Department of

Pharmacology and Toxicology,

Cardiovascular Research Center,

Medical College of Wisconsin, 8701

Watertown Plank Road, Milwaukee, WI 53226, USA.

e-mail: jdimig@mcw.edu
Epoxyeicosatrienoic acids (EETs) contribute importantly to the regulation of vascular tone and blood pressure control. The purpose of this study was to develop stable EET analogs and test their in vivo blood pressure lowering effects in hypertensive rats. Using the pharmacophoric moiety of EETs, ether EET analogs were designed with improved solubility and resistance to auto-oxidation and metabolism by soluble epoxide hydrolase. Ether EET analogs were chosen based on their ability to dilate afferent arterioles and subsequently tested for blood pressure lowering effects in rodent models of hypertension. Initially, 11,12-ether-EET-8-ZE failed to lower blood pressure in angiotensin hypertension or spontaneously hypertensive rats (SHR). Esterification of the carboxylic group of 11,12-ether-EET-8-ZE prevented blood pressure increase in SHR when injected at $2 \mathrm{mg} /$ day for 12 days (MAP $\Delta$ change at day 8 of injection was $-0.3 \pm 2$ for treated and $12 \pm 1 \mathrm{mmHg}$ for control SHR). Amidation of the carboxylic group with aspartic acid produced another EET analog (NUDSA) with a blood pressure lowering effect when injected at $3 \mathrm{mg} / \mathrm{day}$ in SHR for 5 days. Amidation of the carboxylic group with lysine amino acid produced another analog with minimal blood pressure lowering effect. These data suggest that esterification of the carboxylic group of 11,12-ether-EET-8-ZE produced the most effective ether-EET analog in lowering blood pressure in SHR and provide the first evidence to support the use of EET analogs in treatment of cardiovascular diseases.

\section{INTRODUCTION}

Epoxyeicosatrienoic acids (EETs) are synthesized from arachidonic acid by epoxygenase enzymes. These EETs have biological actions that suggest that EETs would be beneficial in combating cardiovascular diseases (Zeldin, 2001; Spector et al., 2004; Imig, 2005; Fleming, 2007). Cardiovascular actions described for EETs include identification as endothelium-derived hyperpolarizing factors, inhibition of leukocyte adhesion to the vascular wall, inhibit vascular smooth muscle migration, promote endothelial cell proliferation, and inhibit platelet aggregation (Campbell et al., 1996; Fisslthaler et al., 1999; Node et al., 1999; Sun et al., 2002; Potente et al., 2003; Krotz et al., 2004; Hercule et al., 2009). EETs have also been demonstrated to preserve organ function when added to a transplantation preservation solution (Yang et al., 2003). Myocardial infarct size following ischemia reperfusion is decreased by the presence of EETs in the reperfusion solution (Seubert et al., 2007; Gross et al., 2008). However, EET or EET analogs have been used with limited success when administered in vivo either acutely or chronically. Given the cardiovascular actions attributed to EETs it has been postulated that modulation of EETs in cardiovascular diseases has potential therapeutic value.

One approach to target EETs for cardiovascular diseases is the development of agonistic analogs for the EETs. EET analogs were developed for in vitro studies because of the limited solubility and storage issues with endogenous EETs (Imig et al., 1999; Falck et al., 2003a). These EET analogs were designed to resist metabolism and improve solubility and facilitated the identification of structure activity relationships for 11,12-EET and 14,15-EET (Falck et al., 2003a; Dimitropoulou et al., 2007; Yang et al., 2007; Falck et al., 2009). EET analogs vasodilate coronary, cerebral, renal and mesenteric arteries, as well as, inhibit vascular smooth muscle cell tumor necrosis factor- $\alpha$-induced vascular cell adhesion molecule- 1 expression (Falck et al., 2003b; Gauthier et al., 2004; Falck et al., 2009; Sudhahar et al., 2010). Evidence has also supported the use of EET analogs in cardiovascular disease. The sulfonimide analog of 11,12-EET (11,12-EET-SI) used in vitro improved vascular function in afferent arterioles taken from hypertensive rats (Imig et al., 2001). EET analogs also decrease heart damage in animal models of cardiac reperfusion injury (Seubert et al., 2007; Gross et al., 2008). Recently 11,12-EET analogs based on the 11-nonyloxy-undec-8$(Z)$-enoic acid structure have been generated with better solubility and resistance to $\beta$-oxidation (Imig and Falck, 2009; Sodhi et al., 2009). One promising EET analog that has been used successfully when administered in vivo is the 11,12-EET analog, NUDSA, that is the aspartic amide of 11-nonyloxy-undec- $8(Z)$-enoic acid (Sodhi et al., 2009). The purpose of the current study was to develop EET analogs and test their in vivo potential to lower blood pressure in rats with hypertension. 


\section{MATERIALS AND METHODS}

\section{EET ANALOG DESIGN AND SYNTHESIS}

11,12-EET analogs were synthesized for use in experimental protocols (Figure 1). The synthesis for the following EET analogs have been previously described; 11,12-ether-EET-8-ZE (Falck et al., 2003b), EET-NOX-8-glyceride (Imig and Falck, 2008a), NUSGLY (Imig and Falck, 2008a), 14,15-Ether-EEZE (Imig and Falck, 2008a), EET-NOX-8-sulfonate (Imig and Falck, 2008b), NUDSA (Sodhi et al., 2009), EET-NOX-8-mann (Imig and Falck, 2008b), and EETNOX-PEG (Imig and Falck, 2008b).

\section{SYNTHESIS OF (S)-7-AMIN0-3-[11-(NONYLOXY)UNDEC-8(Z)-ENAMID0]} HEPTANOIC ACID HYDROCHLORIDE (NUSLY)

2-(7-Aza-1H-benzotriazole-1-yl)-1,1,3,3-tetramethyluronium hexafluorophosphate (HATU; $224 \mathrm{mg}, 0.58 \mathrm{mmol}$ ), $\mathrm{N}_{\mathrm{e}}$-Boc-Llysine methyl ester hydrochloride ( $153 \mathrm{mg}, 0.58 \mathrm{mmol}$ ), and diisopropylethylamine ( $205 \mu \mathrm{L})$ were added sequentially to a stirring, room temperature solution of 11-(nonyloxy)undec-8(Z)-enoic acid $(170 \mathrm{mg}, 0.52 \mathrm{mmol})$ in anhydrous DMF $(5 \mathrm{~mL})$ under an argon atmosphere. After stirring $12 \mathrm{~h}$, the reaction mixture was diluted with EtOAc $(100 \mathrm{~mL})$ and thoroughly washed with water $(3 \times 100 \mathrm{~mL})$, brine $(2 \times 100 \mathrm{~mL})$, dried over $\mathrm{Na}_{2} \mathrm{SO}_{4}$, and evaporated in vacuo. The residue was purified by $\mathrm{SiO}_{2}$ column chromatography eluting with 50\% EtOAc/hexane to afford methyl (S)-7-(tert-butoxycarbonylamino)-3-(11-(nonyloxy)undec-8(Z)enamido)heptanoate $\left(201 \mathrm{mg}, 68 \%\right.$ yield) as a colorless oil. ${ }^{1} \mathrm{H}$ NMR $\left(\mathrm{CDCl}_{3} 300 \mathrm{MHz}\right) \delta 6.07(\mathrm{~d}, J=6.9 \mathrm{~Hz}, 1 \mathrm{H}), 5.44-5.32$ $(\mathrm{m}, 2 \mathrm{H}), 4.61-4.54(\mathrm{~m}, 2 \mathrm{H}), 3.72(\mathrm{~s}, 3 \mathrm{H}), 3.41-3.55(\mathrm{~m}, 4 \mathrm{H})$, $3.12-3.04(\mathrm{~m}, 2 \mathrm{H}), 2.30(\mathrm{q}, J=6.9 \mathrm{~Hz}, 2 \mathrm{H}), 2.20(\mathrm{t}, J=7.8 \mathrm{~Hz}$, $2 \mathrm{H}), 2.02-2.00(\mathrm{~m}, 2 \mathrm{H}), 1.64-1.42(\mathrm{~m}, 16 \mathrm{H}), 1.29-1.24(\mathrm{~m}, 20 \mathrm{H})$, $0.85(\mathrm{t}, J=6.6 \mathrm{~Hz}, 3 \mathrm{H})$.

To a stirring, $0^{\circ} \mathrm{C}$ solution of the above ester $(200 \mathrm{mg}, 0.35 \mathrm{~mm})$ in THF/ $\mathrm{H}_{2} \mathrm{O}(4: 1,5 \mathrm{~mL})$ was added $\mathrm{LiOH}(\sim 2 \mathrm{~mL}, 1 \mathrm{M}$ aqueous solution). After stirring $12 \mathrm{~h}$ at room temperature, the reaction

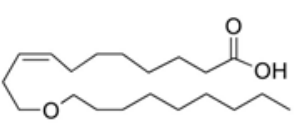

11,12-Ether-EET-8-ZE

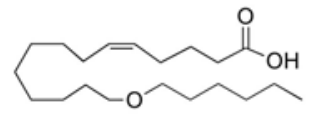

14,15-Ether-EEZE

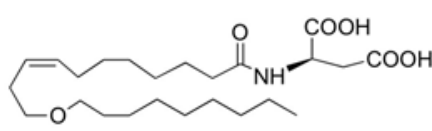

NUDSA

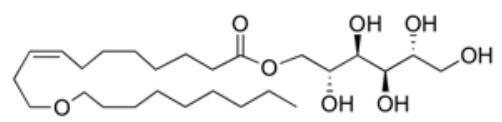

EET-NOX-8-mann<smiles>CCCCCCCCCCCCCCCCCOCCOCCOCCO</smiles>

EET-NOX-8-PEG

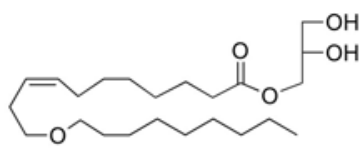

EET-NOX-8-glyceride

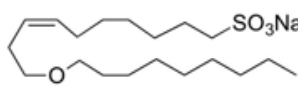

EET-NOX-8-sulfonate

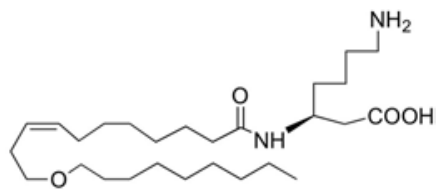

NUSLY

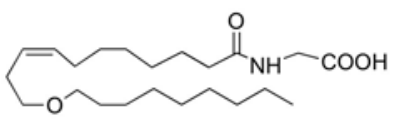

NUSGLY<smiles>CCCCC1(CCCC/C=C\CCCCCO)SC(=O)NC1=O</smiles>

14,15-EET-8-ZE-TZD

FIGURE 1 | Chemical composition of epoxyeicosatrienoic acid (EET) analogs. 
mixture was cooled to $0^{\circ} \mathrm{C}$, acidified to $\mathrm{pH} \sim 4.5$ using oxalic acid ( $\sim 1 \mathrm{~mL}, 1 \mathrm{M}$ aqueous solution), and extracted with EtOAc $(2 \times 50 \mathrm{~mL})$. The combined organic extracts were washed with water $(2 \times 100 \mathrm{~mL})$, brine $(1 \times 100 \mathrm{~mL})$, and dried over $\mathrm{Na}_{2} \mathrm{SO}_{4}$. The solvent was removed in vacuo and the residue was subjected to Boc-deprotection in $\mathrm{THF} / \mathrm{H}_{2} \mathrm{O}(1: 1,5 \mathrm{~mL})$ saturated with $\mathrm{HCl}$ gas. The solvent was evaporated, and dried over high vacuum for $2 \mathrm{~h}$ to afford the title compound ( $65 \mathrm{mg}, 55 \%$ yield). ${ }^{1} \mathrm{H} \mathrm{NMR}\left(\mathrm{MeOH}-\mathrm{d}_{4}\right.$, $300 \mathrm{MHz}) \delta 5.44-5.32(\mathrm{~m}, 2 \mathrm{H}), 4.42-4.34(\mathrm{~m}, 1 \mathrm{H}), 3.41-3.55(\mathrm{~m}$, $4 \mathrm{H}), 2.95-2.82(\mathrm{~m}, 4 \mathrm{H}), 2.29-2.23(\mathrm{~m}, 4 \mathrm{H}), 2.12-1.41(\mathrm{~m}, 14 \mathrm{H})$, $1.37-1.28(\mathrm{~m}, 16 \mathrm{H}), 0.86(\mathrm{t}, J=4.8 \mathrm{~Hz}, 3 \mathrm{H})$.

\section{ANIMALS}

Experiments were conducted using male rats and animal protocols were in accordance with National Institutes of Health guidelines and approved by the Institutional Animal Care and Use Committees. Rats were fed a normal rat chow diet throughout the experiment and were housed under conditions of constant temperature and humidity with a 12:12-h light-dark cycle. Rats were allowed to adapt to these conditions for several days before starting any experimental procedures.

\section{RENAL VASCULAR EXPERIMENTS}

We utilized the in vitro juxtamedullary nephron technique to evaluate the ability of EET analogs to dilate the afferent arteriole. Sprague-Dawley rats were anesthetized with pentobarbital ( $40 \mathrm{mg} /$ $\mathrm{kg}$ body weight i.p.). The right kidney was isolated and after a midline laparotomy, the right renal artery was cannulated through the superior mesenteric artery. The kidney was immediately perfused with a Tyrode's solution containing $6 \%$ albumin and a mixture of L-amino acids. After the microdissection procedures were completed, the renal artery perfusion pressure was set to $100 \mathrm{~mm} \mathrm{Hg}$. The tissue surface was continuously superfused with a Tyrode's solution containing $1 \%$ albumin. After a 20 -min equilibration period, an afferent arteriole was chosen for study, and baseline diameter was measured. After the control period, the afferent arteriole was constricted with phenylephrine and the increase in diameter was assessed in response to increasing concentrations of EET analogs $(0.01 \mathrm{nM}-1 \mu \mathrm{m})$. The afferent arteriole diameter changes to EET analogs were monitored for $3 \mathrm{~min}$ at each concentration. Steady-state diameter to EET analogs was attained by the end of the second minute, and the average diameter at the third minute was used for statistical analysis.

\section{TELEMETRY BLOOD PRESSURE MEASUREMENT}

To accurately detect changes in blood pressure and heart rate, telemetry transmitters (Data Sciences Inc., St. Paul, MN, USA) were implanted in rats 2 weeks prior to the experimental period according to manufacturer's specifications while under sodium pentobarbital anesthesia as previously described (Imig et al., 2005). In brief, a midline incision was used to expose the abdominal aorta that was occluded to allow insertion of the transmitter catheter. The catheter was secured in place with tissue glue and the transmitter body was sutured to the abdominal wall along the incision line as the incision was closed. The skin was closed with staples that were removed 7 days later after the incision had healed. Rats were allowed to recover from surgery and were returned to individual housing.
A baseline arterial pressure was recorded for one week prior to the experimental period. Mean arterial pressure was continuously recorded throughout the experimental period.

\section{ANGIOTENSIN HYPERTENSION}

Telemetry transmitters were implanted into male Sprague-Dawley rats (225-275 g) as described. After a week of basal blood pressure recording, osmotic pumps were implanted (s.c.) to deliver angiotensin at a dose of $60 \mathrm{ng} / \mathrm{min}$ for 3 weeks. In the first series of experiments starting on the first day of pump implantation the 11,12-ether-EET analog was administered (i.p.) once daily for three weeks and blood pressure was continuously monitored. The next series of experiments were conducted 12 days after pump implantation. EET analogs were administered (i.p.) as a single dose on day 12 and blood pressure was monitored for $48 \mathrm{~h}$.

\section{SPONTANEOUSLY HYPERTENSIVE RATS}

Telemetry transmitters were implanted into male spontaneously hypertensive rats (SHR) as described. After the surgical recovery period, baseline mean arterial pressure was recorded for 1 week. In this series of experiments EET analogs were administered (i.p.) once daily for various number of days and blood pressure was continuously monitored. Administration of EET analogs was stopped and blood pressure monitored for 4 days after treatment withdrawal.

\section{DETERMINATION OF NUDSA BY LIOUID CHROMATOGRAPHY- ELECTROSPRAY IONIZATION-MASS SPECTROMETRY}

Samples were analyzed by LC-ESI-MS (Agilent 1100 LC/MSD, SL model). Briefly, the samples $(5 \mu \mathrm{l})$ were separated on a reverse phase $\mathrm{C}_{18}$ column (Kromasil, $250 \times 2 \mathrm{~mm}$ ) using water/acetonitrile containing $0.005 \%$ acetic acid as a mobile phase at the flow rate of $0.20 \mathrm{~mL} / \mathrm{min}$. The mobile phase started at $90 \%$ methanol for $2 \mathrm{~min}$, linearly increased to $100 \%$ methanol in $10 \mathrm{~min}$, and held for $10 \mathrm{~min}$. Drying gas flow was $12 \mathrm{l} / \mathrm{min}$, drying gas temperature was $350^{\circ} \mathrm{C}$, nebulizer pressure was $35 \mathrm{psig}$, vaporizer temperature was $325^{\circ} \mathrm{C}$, capillary voltage was $3000 \mathrm{~V}$, and fragmentor voltage was $120 \mathrm{~V}$. The detection was made in the negative mode. For quantitative measurements, the $m / z 440$ and 311 were used for NUDSA and $\left[{ }^{2} \mathrm{H}_{8}\right]-\mathrm{AA}$, respectively. The concentrations of compounds in the samples were calculated from the ratios of peak areas to internal standard and compared with the standard curves.

\section{STATISTICAL ANALYSIS}

All data are presented as mean \pm SEM. Mean arterial blood pressure and \% afferent arteriolar relaxation data were analyzed using analysis of variance (ANOVA) for repeated measurements. Differences were considered statistically significant with $p<0.05$ compared to the control. Analyses were performed using GraphPad Prism Version 4.0 software (GraphPad Software Inc, La Jolla, CA, USA).

\section{RESULTS}

\section{EET ANALOGS}

Experimental studies of EET analogs in vivo have been hampered by difficulties with stability and storage. A series of EET analogs was developed and designed to resist esterification, $\beta$-oxidation 
and/or metabolism by sEH. Figure 1 depicts the chemical structures of the EET analogs that were synthesized and tested initially for vascular activity.

\section{EET ANALOG VASCULAR ACTIONS}

We have previously demonstrated that 11,12-ether-EET-8-ZE increased mesenteric resistance artery and afferent arteriolar diameter to a similar extent as the endogenous metabolite 11,12-EET (Dimitropoulou et al., 2007; Imig et al., 2008). For this study, we assessed the afferent arteriolar diameter response to a series of nine EET analogs and compared them to 11,12-ether-EET-8-ZE. The EET analogs demonstrated a variable ability to dilate afferent arterioles. Afferent arteriolar dilation to the EET analogs became evident at concentration of $1 \mathrm{nM}$ and reached a maximum at $10 \mu \mathrm{M}$. Four of the EET analogs dilated the afferent arteriole to a degree similar to 11,12-ether-EET-8-ZE (Figure 2). These four EET analogs with activity similar to 11,12-ether-EET-8-ZE as well as an EET analog with lesser vasodilatory activity were then assessed for their ability to lower blood pressure in hypertension rat models.

\section{EET analogs on blood pressure}

We initially assessed the ability of 11,12-ether-EET-8-ZE to lower blood pressure in angiotensin and SHR hypertension. Figure 3, top panel depicts the effects of 11,12-ether-EET-8-ZE $(1 \mathrm{mg} / \mathrm{d}$ i.p.) administered once daily for three weeks on blood pressure angiotensin hypertension. 11,12-ether-EET-8-ZE did not alter the progressive increase in blood pressure in response to chronic angiotensin infusion. The result of higher 11,12-ether-EET-8-ZE doses $(10 \mathrm{mg} / \mathrm{d}$ or $50 \mathrm{mg} / \mathrm{d}$ i.p.) administered to SHR is depicted in the bottom panel of Figure 3. As with angiotensin hypertension, 11,12-ether-EET-8-ZE did not decrease mean arterial blood pressure when administered to SHR.

Next, we compared the ability of a bolus dose of the EET analogs, NUDSA (1 mg i.p.) and NUSGLY (1 mg i.p.) with excellent dilator activity to an EET analog, EET-NOX-8-glyceride (1 mg i.p.) with lesser dilator activity to lower blood pressure in angiotensin hypertension. NUDSA and EET-NOX-8-glyceride both transiently lowered blood pressure in rats with angiotensin hypertension. Blood pressure in angiotensin hypertensive rats averaged $152 \pm 4 \mathrm{mmHg}$ and decreased by $52 \mathrm{mmHg}$ within $2 \mathrm{~h}$ after administration of NUDSA, by $46 \mathrm{mmHg}$ in response to NUSGLY, and by $58 \mathrm{mmHg}$ in response to EET-NOX-8-glyceride (Figure 4). The decrease in blood pressure to EET-NOX-8-glyceride was very transient and blood pressure increased to hypertensive levels by the third hour. On the other hand, blood pressure remained lower in NUDSA and NUSGLY treated animals throughout the 24 -h period and leveled of at $135 \pm 6$ and $143 \pm 5 \mathrm{mmHg}$, respectively, during the last $8 \mathrm{~h}$. Heart rate averaged $394 \pm 7 \mathrm{bpm}$ and did not change in response to NUDSA, NUSGLY, or EET-NOX-8-glyceride administration. These results suggested that EET analogs with excellent dilator activity could be more effective in lowering blood pressure when administered chronically to hypertensive animals.

We then tested five EET analogs for their ability to lower blood pressure in SHR. Comparison of an EET analog with full to an EET analog with intermediate vasodilator activity is depicted in Figure 5. The blood pressure response in SHR treated with EET-NOX-8-glyceride (3 mg/d i.p.) or NUSLY (2 mg/d i.p.)

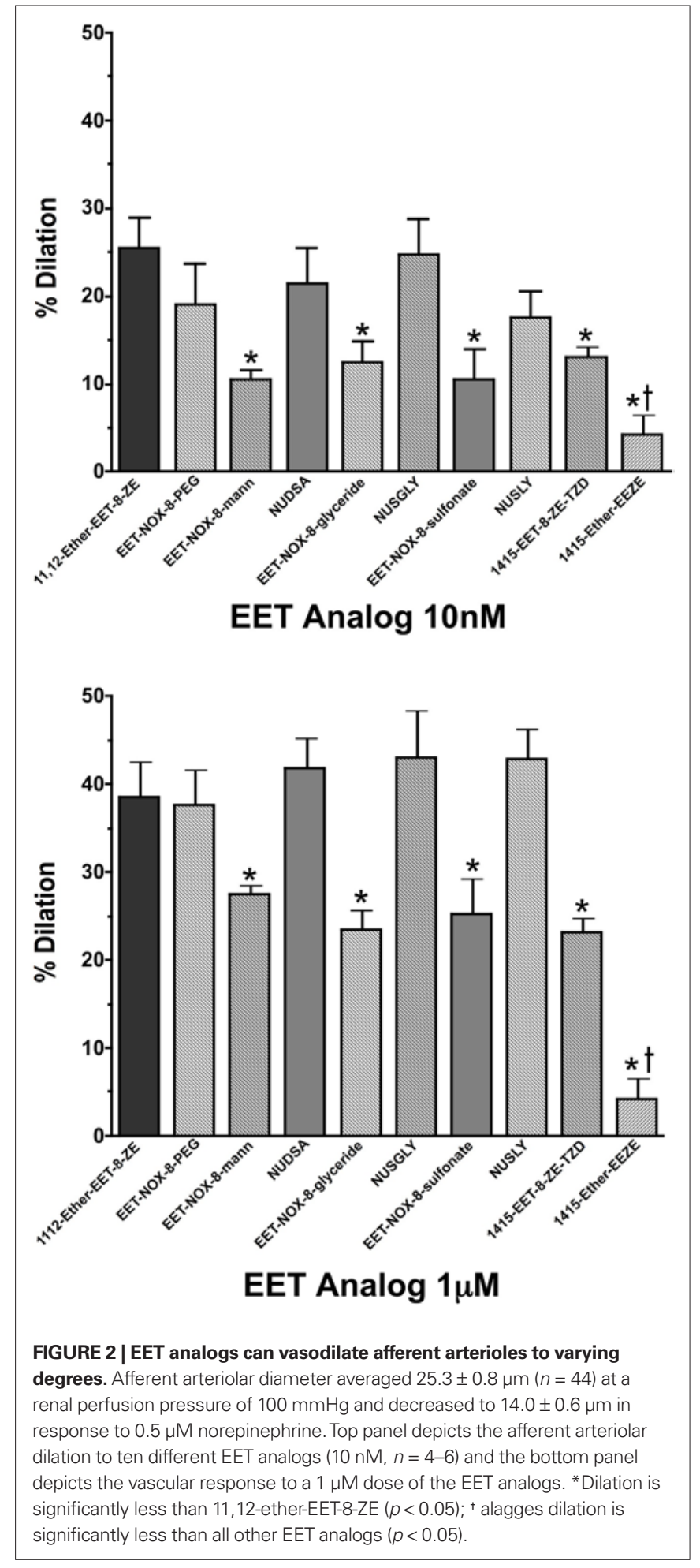

demonstrates that EET analogs with full vasodilator capacity lower blood pressure to a greater extent in SHR. Once daily administration for 5 days with EET-NOX-8-glyceride caused a minimal decrease in blood pressure whereas NUSLY decreased blood pressure by $10 \mathrm{mmHg}$ after 5 days $(p<0.05)$ and this 


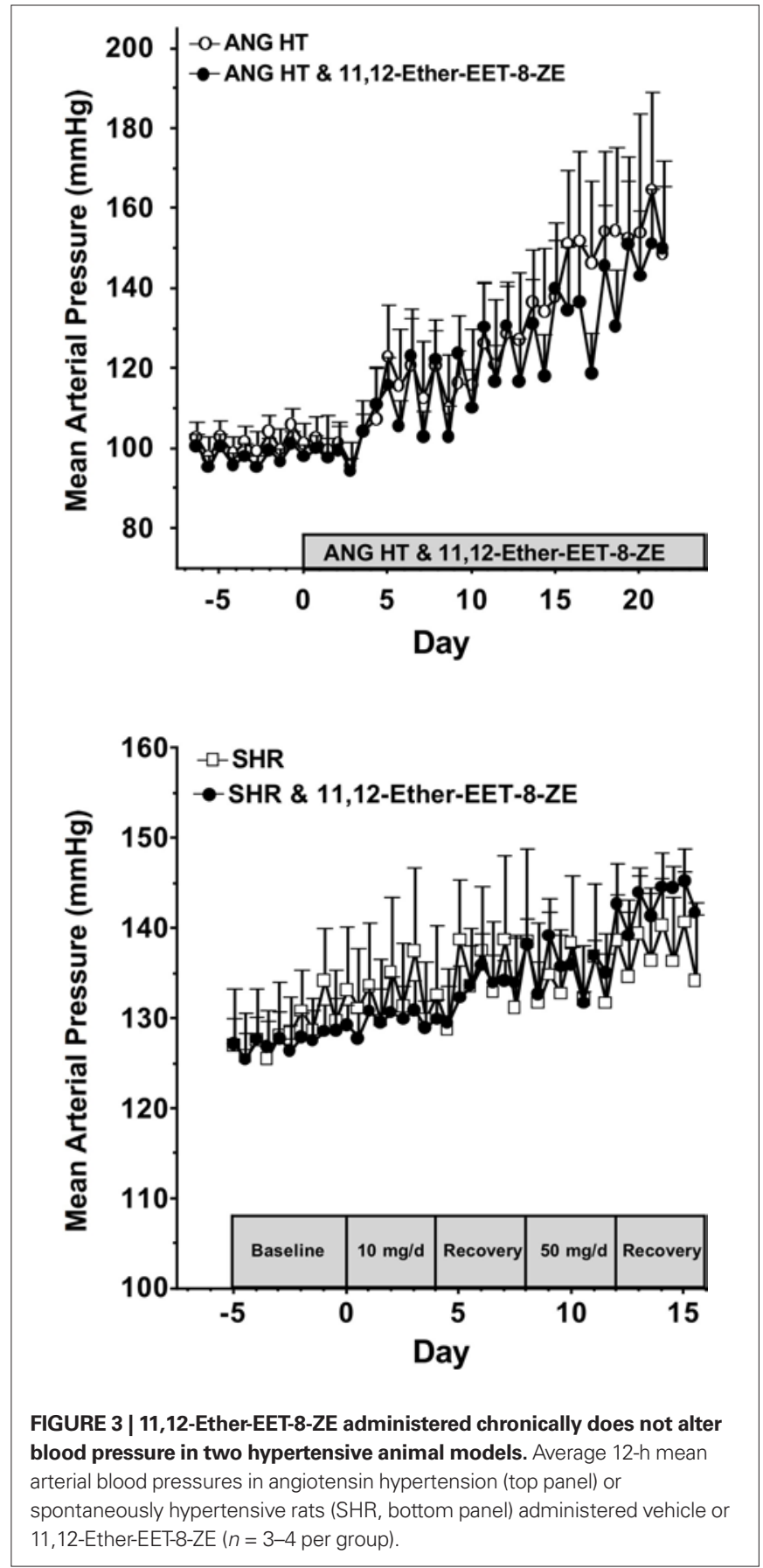

decrease in blood pressure waned in the last 2 days. The results of two additional EET analogs with excellent dilator activity and an ability to lower blood pressure in the SHR are depicted in Figure 6. EET-NOX-8-PEG (2 mg/d i.p.) administered once daily for 10 days to SHR decreased blood pressure $10-15 \mathrm{mmHg}$ ( $p<0.05$, top panel). Once daily administration of NUSGLY ( $2 \mathrm{mg} / \mathrm{d}$ i.p.) for 8 days lowered blood pressure by $15 \mathrm{mmHg}$ in SHR $(p<0.05$, bottom panel). In each instance blood pressure began to increase in the SHR when the EET analog treatment was discontinued. Taken together, these data suggests that EET

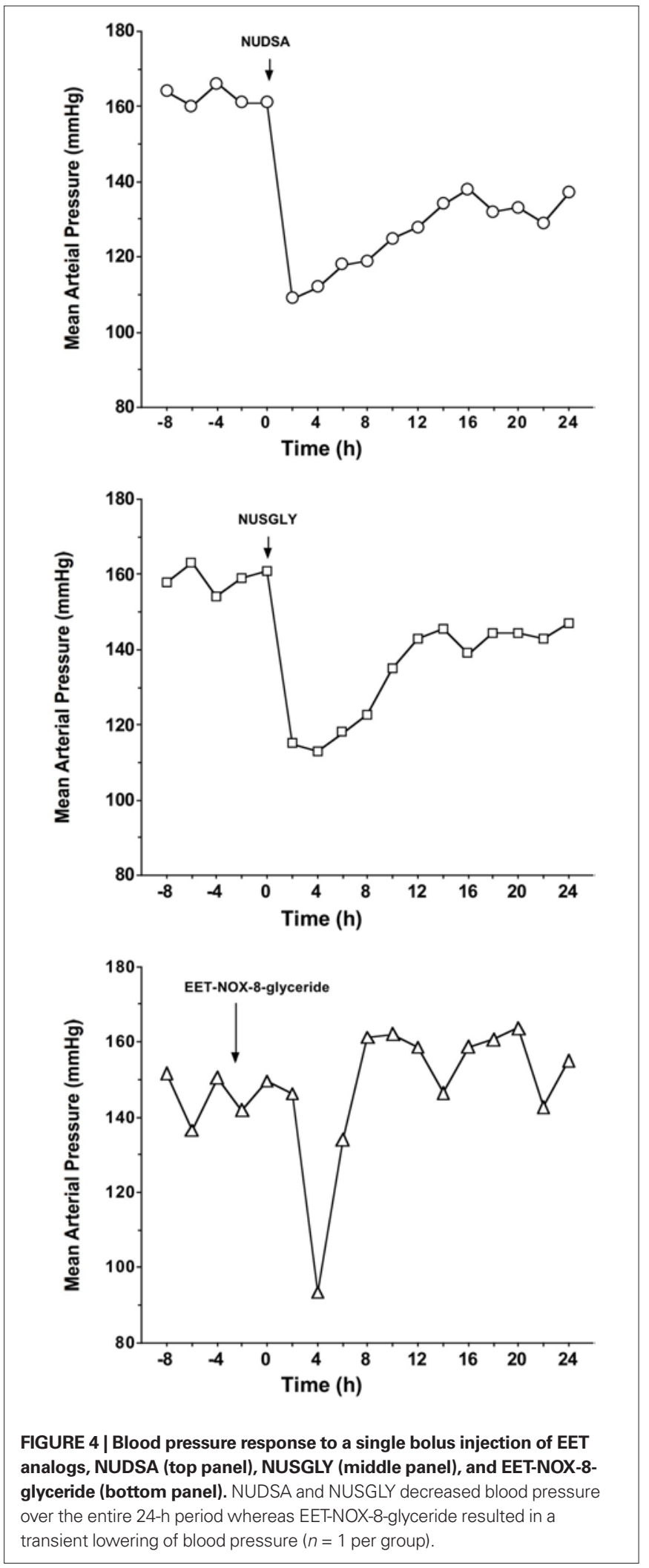

analog dilator activity is just one aspect that can predict in vivo blood pressure lowering but other aspects such as bioavailability may limit this biological action. 

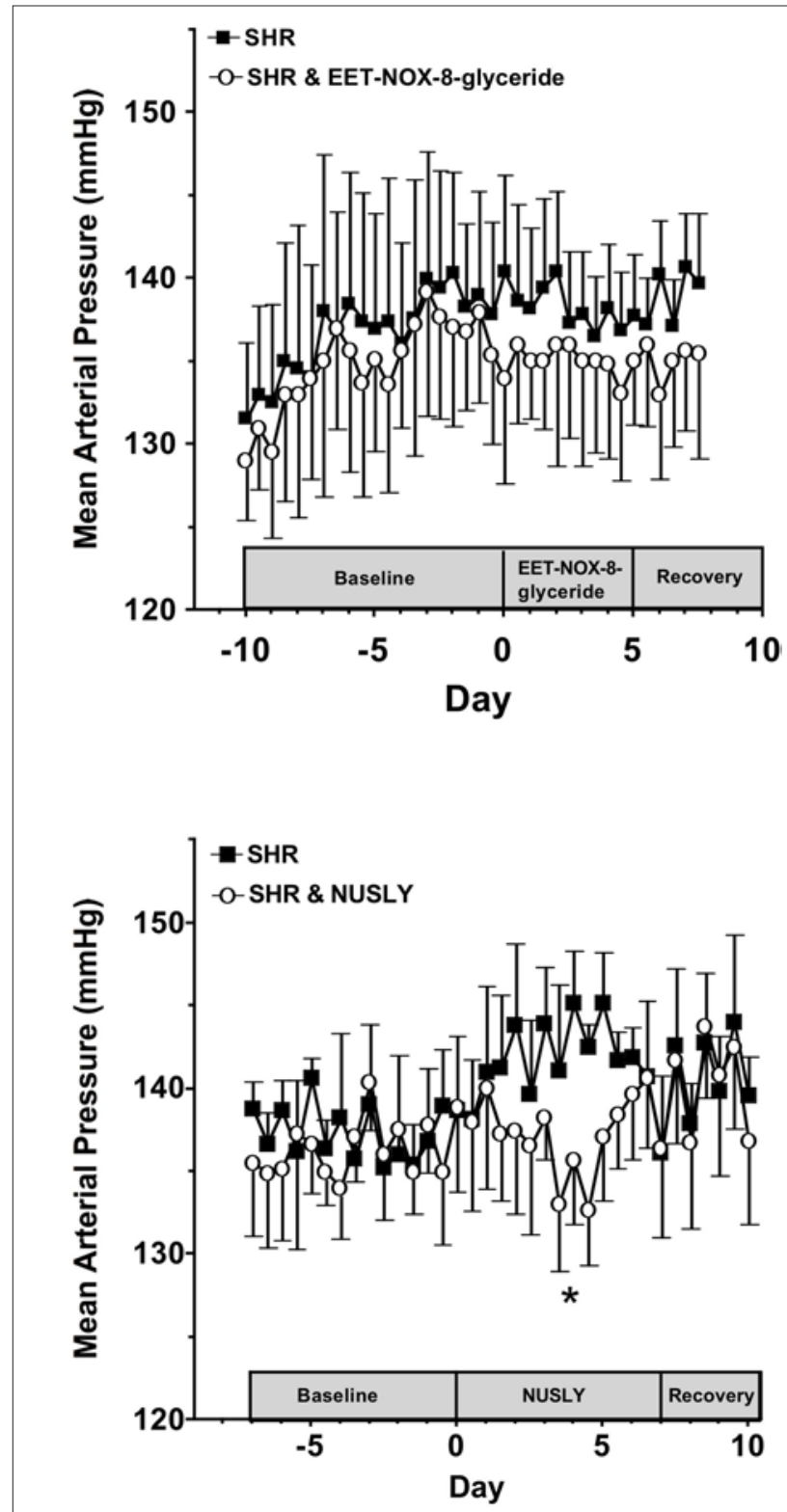

FIGURE 5 | Comparison of an EET analog with intermediate vasodilator activity, EET-NOX-8-glyceride, to on with full vasodilator activity, NUSLY on blood pressure in spontaneously hypertensive rats (SHR). Average 12-h mean arterial blood pressures in SHR administered EET-NOX-8-glyceride for 5 days (top panel) or NUSLY for one week (bottom panel) compared to vehicle ( $n=3-4$ per group). *Blood pressure is significantly less than vehicle treated SHR $(p<0.05)$.

\section{NUDSA ON BLOOD PRESSURE AND PLASMA LEVELS}

Next we tested the effect of NUDSA that had excellent vasodilator activity and has previously been demonstrated to lower blood pressure in a mouse model of metabolic syndrome (Sodhi et al., 2009). Administration of NUDSA ( $3 \mathrm{mg} / \mathrm{d}$ i.p.) for 5 days lowered blood pressure by $10 \mathrm{mmHg}$ in SHR ( $p<0.05$, Figure 7 , top panel). We then developed an analytical method to measure plasma levels of our lead EET analog, NUDSA that demonstrated in vivo blood pressure lowering in angiotensin hypertension and SHR. A quantitative
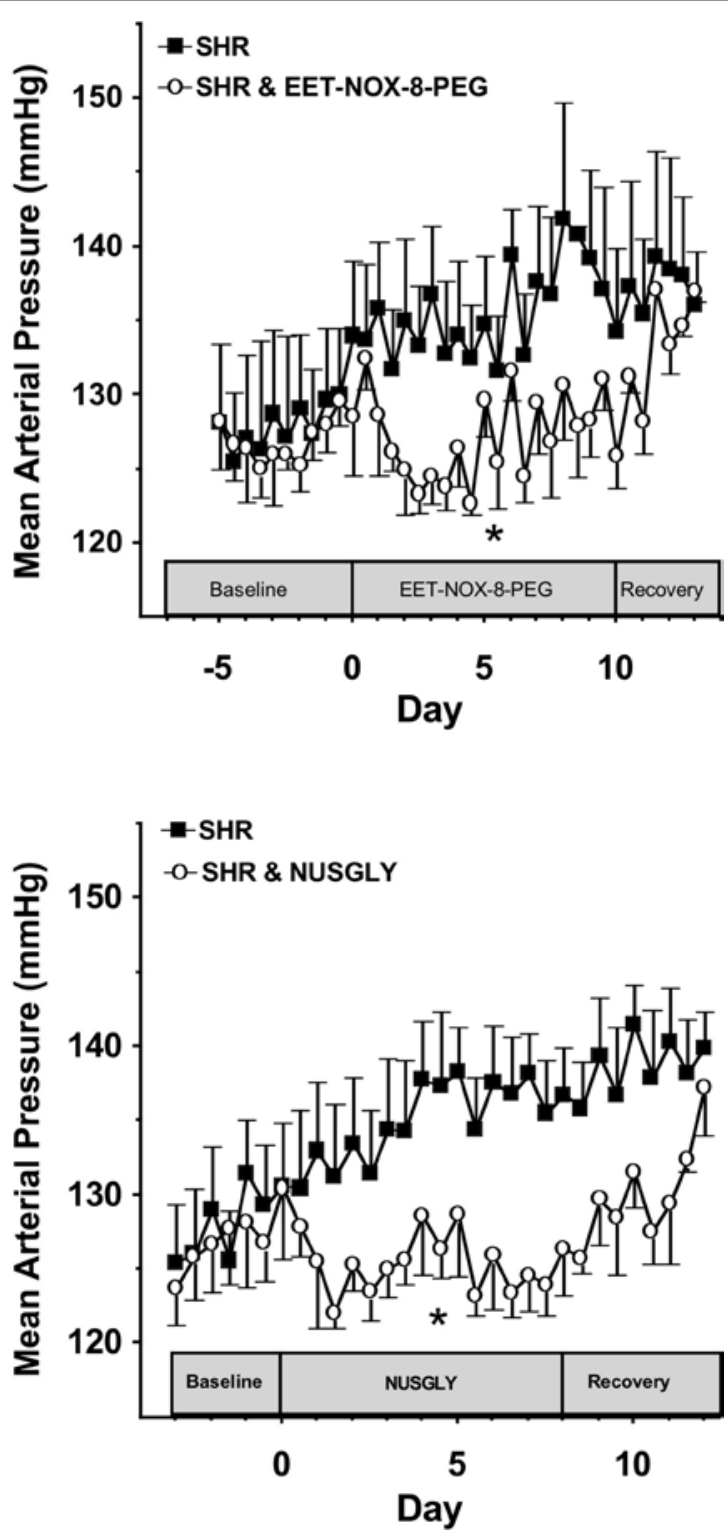

FIGURE 6 |Two EET analogs administered chronically decrease blood pressure in spontaneously hypertensive rats (SHR). Average 12-h mean arterial blood pressures in SHR administered EET-NOX-8-PEG for ten days (top panel) or NUSGLY for 8 days (bottom panel) compared to vehicle ( $n=3-4$ per group). ${ }^{*}$ Blood pressure is significantly less than vehicle treated SHR $(p<0.05)$.

LC/MS method that has a sensitivity to measure $300 \mathrm{pg}$ of NUDSA in a plasma sample. NUDSA administered as a bolus injection resulted in detectable plasma levels for up to $4 \mathrm{~h}$ (Figure 7, bottom panel). There was also very little evidence for rapid metabolism of NUDSA. These data demonstrate that NUDSA is bioavailable and plasma levels can reach a level that correlates with the anti-hypertensive actions.

\section{DISCUSSION}

Epoxyeicosatrienoic acids have cardiovascular actions that implicate them as important contributors to vascular function and blood pressure control (Zeldin, 2001; Spector et al., 2004; Imig, 2005; 

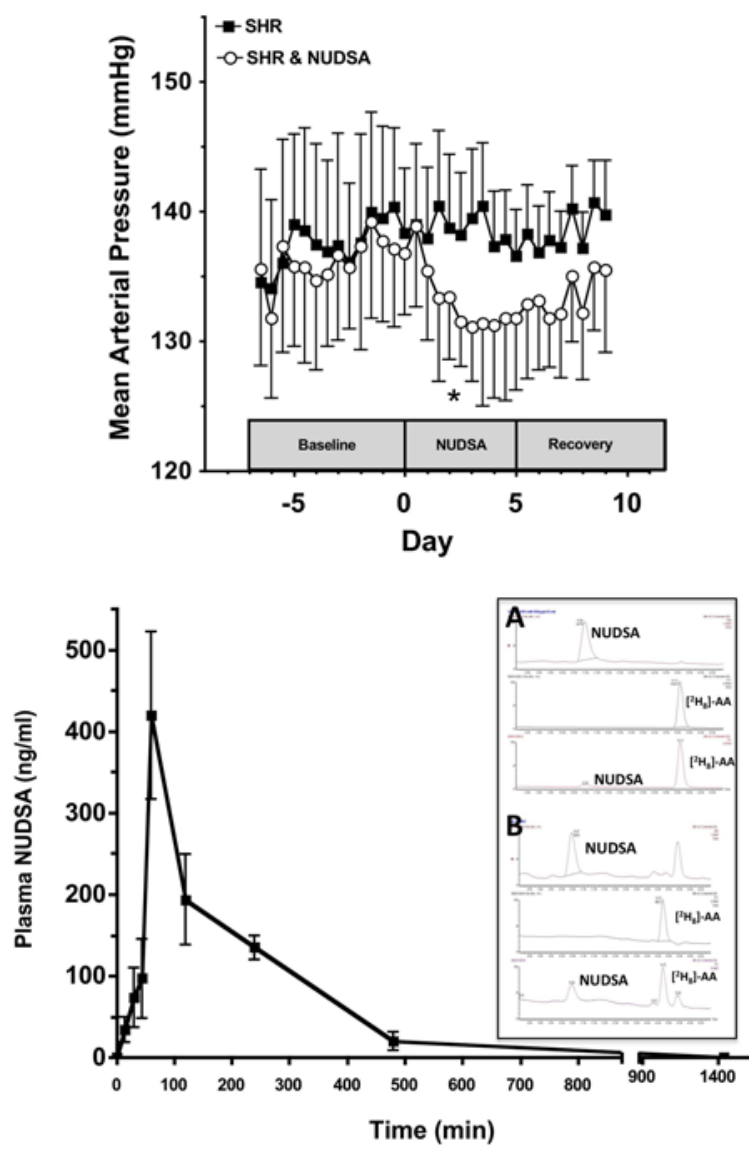

FIGURE 7 | NUDSA decreases blood pressure in blood pressure in spontaneously hypertensive rats (SHR). Average 12-h mean arterial blood pressures in SHR administered NUDSA for 5 days (top panel). Time course for NUDSA plasma concentration after i.p. administration to rats. Graph depicts increase in plasma NUDSA over a 1-day period (bottom panel). LC-MS was able to detect NUDSA (inset). Inset: (A) Top depicts NUDSA standard, middle depicts $\left[{ }^{2} \mathrm{H}_{8}\right]$-arachidonic acid standard and bottom depicts combined. Inset: (B) Same as panel A from a plasma sample. *Blood pressure is significantly less than vehicle treated SHR $(p<0.05)$

Fleming, 2007). An avenue being explored for potential therapeutic application is the development of EET analogs. EET analogs have the potential to have greater beneficial effects in hypertension since EETs have anti-inflammatory and anti-platelet aggregatory properties (Falck et al., 2003b; Krotz et al., 2004; Imig et al., 2005). We generated a series of 11,12-EET analogs and determined their vascular actions in vitro and subsequently tested a subset of this series for their ability to lower blood pressure in hypertension when administered chronically. We found that esterification of the carboxylic group of 11,12-ether-EET-8-ZE with aspartic acid produced the most effective anti-hypertensive EET analog in the series.

Epoxyeicosatrienoic acids analogs of 11,12-EET and 14,15-EET and EET antagonists have been used for many years to examine the cardiovascular actions attributed to EETs (Gauthier et al., 2004; Sudhahar et al., 2010). In particular, analogs of 11,12-EET and 14,15-EET have been used to identify structure activity relationships and cell signaling mechanisms that are responsible for vasodilation (Falck et al., 2003a; Dimitropoulou et al., 2007; Imig et al., 2008). These studies have determined that an acidic carboxyl group in carbon 1 , an $\Delta^{8}$ double bond, 20-carbon chain length, and a cis epoxide are required for full vasodilator activity (Falck et al., 2003a; Dimitropoulou et al., 2007; Imig et al., 2008). We have previously determined that 11,12-ether-EET-8-ZE dilated renal and mesenteric arteries to an extent similar to endogenous 11,12-EET (Dimitropoulou et al., 2007; Imig et al., 2008). A series of analogs were then synthesized and tested for afferent arteriolar dilator activity. Modifications were made to the carboxylic group of 11,12-ether-EET-8-ZE to confer resistance to $\beta$-oxidation. 11,12 -EET analogs containing an $\Delta^{8}$ double bond and an ether at the 11,12 position dilated afferent arterioles. Three of these EET analogs were similar to 11,12-ether-EET-8-ZE in respect to vasodilatory capacity. Other modifications to the carboxylic group resulted in EET analogs with an intermediate ability to dilate afferent arterioles. As would be expected, 14,15-ether-EEZE that lacks an $\Delta^{8}$ double bond failed to dilate the afferent arteriole. These findings determined that modifications to the carboxylic group of 11,12-ether-EET-8-ZE result in EET analogs that have similar or slightly diminished vasodilatory activity.

Even though EET analogs have been used in cell culture and in vitro systems for many years, there has been limited success with in vivo administration in either the acute or chronic setting. 11,12-Ether-EET-8-ZE did not alter blood pressure in angiotensin hypertension or SHR when administered chronically for a period of days and weeks. Since 11,12-ether-EET-8-ZE contains a carboxylic group that is susceptible to esterification and $\beta$-oxidation, we developed another series of EET analogs. In this study we determined that modification of the carboxylic group to resist $\beta$-oxidation resulted in EET analogs that decreased blood pressure in hypertension. Interestingly, EET-NOX-8-glyceride that had intermediate vasodilatory activity transiently decreased blood pressure in angiotensin hypertension and did not significantly lower blood pressure in the SHR when administered over a 5-day period. On the other hand, NUDSA that vasodilated the afferent arteriole similar to 11,12-ether-EET-8-ZE decreased blood pressure in angiotensin hypertension over a 24 -h period and decreased blood pressure over a 5-day period in SHR. These decreases in blood pressure were not accompanied by a change in heart rate. A recent study determined the ability of NUDSA to ameliorate the metabolic syndrome phenotype in heme-oxygenase 2 null mice (Sodhi et al., 2009). NUDSA decreased blood pressure and prevented obesity-associated vascular and kidney damage in metabolic syndrome mice (Sodhi et al., 2009). This study and the results of the current study demonstrate a first step toward the therapeutic application of EET analogs for cardiovascular diseases.

One aspect that was not determined in the experimental study where mice were chronically administered NUDSA was bioavailability. We developed an LC-MS method to determine NUDSA levels in rat plasma. An injection of NUDSA was given and plasma levels determined at different time points. Plasma levels of NUDSA peaked $2 \mathrm{~h}$ after administration and were significantly lower at $8 \mathrm{~h}$. We did not determine clearance, metabolism, or tissue NUDSA levels in the current study. A more thorough pharmacokinetic analysis would be necessary if this or another EET analog was developed for preclinical trials. 
In conclusion, we developed a series of EET analogs and evaluated their ability to dilate afferent arterioles and lower blood pressure in angiotensin hypertension and SHR. Amidation of the 11,12-ether-EET-8-ZE carboxylic group with aspartic acid resulted in a promising EET analog that possessed vasodilatory activity and lowered blood pressure in hypertension. These experimental findings provide evidence for the possible future use of EET analogs for the treatment of cardiovascular diseases.

\section{REFERENCES}

Campbell, W. B., Gebremedhin, D., Pratt, P. F., and Harder, D. R. (1996). Identification of epoxyeicosatrienoic acids as endothelium-derived hyperpolarizing factors. Circ. Res. 78, 415-423.

Dimitropoulou, C., West, L., Field, M. B., White, R.E., Reddy,L.M.,Falck,J.R., and Imig, J. D. (2007). Protein phosphatase $2 \mathrm{~A}$ and $\mathrm{Ca}^{2+}$-activated $\mathrm{K}+$ channels contribute to 11,12-epoxyeicosatrienoic acid analog mediated mesenteric arterial relaxation. Prostaglandins Other Lipid Mediat. 83, 50-61.

Falck, J. R., Kodela, R., Manne, R., Atcha, R., Puli, N., Dubasi, N., Manthati, V. L., Capdevila, J. H., Yi, X.Y., Goldman, D. H., Morisseau, C., Hammock, B. D., and Campbell, W. B. (2009). 14,15Epoxyeicosa-5,8,11-trienoic acid (14,15-EET) surrogates containing epoxide bioisosteres: influence upon vascular relaxation and soluble epoxide hydrolase inhibition. J. Med. Chem. 52, 5069-5075.

Falck, J. R., Krishna, U. M., Reddy, Y. K., Kumar, P. S., Reddy, K. M., Hittner, S. B., Deeter, C., Sharma, K. K., Gauthier, K. M., and Campbell, W. B. (2003a). Comparison of vasodilatory properties of 14,15-EET analogs: structural requirements for dilation. Am. J. Physiol. Heart Circ. Physiol. 284, H337-H349.

Falck, J. R., Reddy, L. M., Reddy, Y. K., Bondlela, M., Krishna, U. M., Ji, Y., Sun, J., and Liao, J. K. (2003b). 11,12epoxyeicosatrienoic acid (11,12-EET): structural determinants for inhibition of TNF-alpha-induced VCAM-1 expression. Bioorg. Med. Chem. Lett. 13, 4011-4014

Fisslthaler, B., Popp, R., Kiss, L., Potente, M., Harder, D. R., Fleming, I., and Busse, R. (1999). Cytochrome P450 $2 \mathrm{C}$ is an EDHF synthase in coronary arteries. Nature 401, 493-497.

Fleming, I. (2007). Epoxyeicosatrienoic acids, cell signaling and angiogenesis. Prostaglandins Other Lipid Mediat. 82, 60-67.

Gauthier, K. M., Falck, J. R., Reddy, L. M., and Campbell, W. B. (2004). 14,15-EET analogs: characterization of structural requirements for agonist and antagonist activity in bovine coronary arteries. Pharmacol. Res. 49, $515-524$.
Gross, G. J., Gauthier, K. M., Moore, J., Falck, B., and Nithipatikom, K. (2008). Effects of the selective EET antagonist, 14,15EEZE, on cardioprotection produced by exogenous or endogenous EETs in the canine heart. Am. J. Physiol. Heart Circ. Physiol. 294, H2838-H2844.

Hercule, H. C., Schunck, W. H., Gross, V., Seringer, J., Leung, F. P., Weldon, S. M., da Costa Gonclalves, A. C. H., Huand, Y., Luft, F. C., and Gollasch, M. (2009). Interaction between $\mathrm{P} 450$ eicosanoids and nitric oxide in the control of arterial tone in mice. Aterioscler. Thromb.

Imig, J. D. (2005). Epoxide hydrolase and epoxygenase metabolites as therapeutic targets for renal diseases. Am. J. Physiol. Renal Physiol. 289, F496-F503.

Imig, J.D., Dimitropoulou, C., Reddy, D. S., White, R. E., and Falck, J. R. (2008). Afferent arteriolar dilation to 11, 12-EET analogs involves PP2A activity and $\mathrm{Ca} 2+$-activated $\mathrm{K}+$ Channels. Microcirculation 15, 137-150.

Imig, J. D., and Falck, J. R. (2008a). Compositions and methods for the treatment of renal and cardiovascular disease. U.S. Pat. Appl. Publ., Cont.in-part of U.S. Ser. No. 866,395. US 2008153889 A1 20080626 CAN 149:104528 AN 2008:773879.

Imig, J. D., and Falck, J. R. (2008b). 11Nonyloxyundec-8(Z)-enoic acid and derivatives for the treatment of renal and cardiovascular disease. U.S. Pat. Appl. Publ. US 2008146663 A1 20080619 CAN 149:70453 AN 2008:743378.

Imig, J. D., and Falck, J. R. (2009). Compositions and methods for the treatment of renal and cardiovascular disease. US Patent \#7,550,617.

Imig, J. D., Inscho, E. W., Deichmann, P. C., Reddy, K. M., and Falck, J. R. (1999). Afferent arteriolar vasodilation to the sulfonimide analog of 11 , 12-epoxyeicosatrienoic acid involves protein kinase A. Hypertension 33, 408-413.

Imig, J. D., Zhao, X., Falck, J. R., Wei, S., and Capdevila, J.H. (2001). Enhanced renal microvascular reactivity to angiotensin II in hypertension is ameliorated by the sulfonimide analog of 11,12-epoxyeicosatrienoic acid. J. Hypertens. 19, 983-992. J. R., Hammock, B. D., Campbell, W. Vasc. Biol. 29, 54-60.

\section{PATENTS}

U.S. Patent \#7,732,470: JD Imig, JR Falck. Issued June 8, 2010. U.S. Patent \#7,550,617: JD Imig, JR Falck. Issued June 23, 2009.

\section{ACKNOWLEDGMENTS}

We thank Sean Shaw and Binaya Shrestha for technical assistance with experimental studies. This work was supported by NIH grants HL59699, GM31278, and DK38226, the Robert A. Welch Foundation, and Advancing a Healthier Wisconsin.

Imig, J. D., Zhao, X., Zaharis, C. Z. Olearczyk, J. J., Pollock, D. M. Newman, J. W., Kim, I. H., Watanabe, T., and Hammock, B. D. (2005) An orally active epoxide hydrolase inhibitor lowers blood pressure and provides renal protection in saltsensitive hypertension. Hypertension 46, 975-981.

Krotz, F., Riexinger, T., Buerkle, M. A., Nithipatikom, K., Gloe, T., Sohn, H.Y. Campbell, W. B., and Pohl, U. (2004). Membrane-potential-dependent inhibition of platelet adhesion to endothelial cells by epoxyeicosatrienoic acids. Arterioscler. Thromb. Vasc. Biol. 24 595-600.

Node, K., Huo, Y., Ruan, X., Yang, B., Spiecker, M., Ley, K., Zeldin, D. C., and Liao, J. K. (1999). Anti-inflammatory properties of cytochrome P450 epoxygenase-derived eicosanoids. Science 285, 1276-1279.

Potente, M., Fisslthaler, B., Busse, R. and Fleming, I. (2003). 11,12Epoxyeicosatrienoic acid-induced inhibition of FOXO factors promotes endothelial proliferation by downregulating p27Kip1. J. Biol. Chem. 278, 29619-29625.

Seubert, J.M., Zeldin, D. C., Nithipatikom, K., and Gross, G. J. (2007). Role of epoxyeicosatrienoic acids protecting the myocardium following ischemia / reperfusion injury. Prostaglandins Other Lipid Mediat. 82, 50-59.

Sodhi, K., Inoue, K., Gotlinger, K. H., Canestraro, M., Vanella, L., Kim, D. H., Manthati, V. L., Koduru, S. R., Falck, J. R., Schwarzman, M. L., and Abraham, N. G. (2009). Epoxyeicosatrienoic acid agonist rescues metabolic syndrome phenotype of HO-2-null mice. J. Pharmacol. Exp. Ther. 331, 906-916.

Spector, A. A., Fang, X., Snyder, G. D., and Weintraub, N. L. (2004). Epoxyeicosatrienoic acids (EETs): metabolism and biochemical function. Prog. Lipid Res. 43, 55-90.

Sudhahar, V., Shaw, S., and Imig, J. D. (2010). Epoxyeicosatrienoic acid analogs and vascular function. Curr. Med. Chem. 17, 1181-1190.

Sun, J., Sui, X., Bradbury, J. A., Zeldin, D. C., Conte, M. S., and Liao, J. K. (2002). Inhibition of vascular smooth muscle cell migration by cytochrome p450 epoxygenase-derived eicosanoids. Circ. Res. 90, 1020-1027.

Yang, Q., Zhang, R. Z., Yim, A. P., and He, G. W. (2003). Effect of 11,12epoxyeicosatrienoic acid as an additive to St. Thomas' cardioplegia and University of Wisconsin solutions on endothelium-derived hyperpolarizing factor-mediated function in coronary microarteries: influence of temperature and time. Ann. Thorac. Surg. 76, 1623-1630.

Yang, W., Holmes, B. B., Gopal, V. R., Kishore, R. V., Sangras, B., Yi, X. Y., Falck, J. R., and Campbell, W. B. (2007). Characterization of 14,15 epoxyeicosatrienoyl-sulfonamides as 14,15-epoxyeicosatrienoic acid agonists: use for studies of metabolism and ligand binding. J. Pharmacol. Exp. Ther. 321, 1023-1031.

Zeldin, D. C. (2001). Epoxygenase pathways of arachidonic acid metabolism. J. Biol. Chem. 276, 36059-36062.

Conflicts of Interest Statement: The author declares that the research was conducted in the absence of any commercial or financial relationships that could be construed as a potential conflict of interest.

Received: 20 August 2010; paper pending published: 08 September 2010; accepted: 17 November 2010; published online: 03 December 2010.

Citation: Imig JD, Elmarakby A, Nithipatikom K, Wei S, Capdevila JH, Tuniki VR, Sangras B, Anjaiah S, Manthati VL, Reddy DS and Falck JR (2010) Development of epoxyeicosatrienoic acid analogs with in vivo anti-hypertensive actions. Front. Physio. 1:157. doi: 10.3389/ fphys.2010.00157

This article was submitted to Frontiers in Vascular Physiology, a specialty of Frontiers in Physiology.

Copyright (c) 2010 Imig, Elmarakby, Nithipatikom, Wei, Capdevila, Tuniki, Sangras, Anjaiah, Manthati, Reddy and Falck. This is an open-access article subject to an exclusive license agreement between the authors and the Frontiers Research Foundation, which permits unrestricted use, distribution, and reproduction in any medium, provided the original authors and source are credited. 